\title{
Helicobacter Pylori Infection and Risk of Variceal Bleeding among Patients with Liver Cirrhosis
}

\author{
Yosry AM ${ }^{(1)}$, Mostafa AE ${ }^{(2)}$, Mohamed MSA ${ }^{(3)}$ \\ (1) Professor of hepatology, gastroenterology and infectious diseases faculty of \\ medicine Al-Azhar university \\ (2) Assistant professor of hepatology, gastroenterology and infectious diseases faculty \\ of medicine Al-Azhar university \\ (3) Department of hepatology, gastroenterology and infectious diseases faculty of \\ medicine Fayoum university
}

\begin{abstract}
Inflammatory changes in the stomach caused by Helicobacter pylori indirectly and directly affect liver function. Moreover, the bacteria may worsen the course of the liver cirrhosis. The incidence of portal hypertension and esophageal varices correlates with the incidence of $\mathrm{H}$. pylori infection. This study aims to detect $H$. pylori infection among patients with liver cirrhosis correlation with the degree of liver injury according to Child-Pugh classification and the
\end{abstract}

stage of esophageal varices and its bleeding. This study was conducted in Hepatology and Gastroenterology and Infectious diseases of Al_Azhar medical Department from December 2018 till November 2020. 50 patients were included in bleeder group 32 patient had H.pylori and 18 patient negative H.pylori. 50 patient were included in non_bleeder group 28 patient had H.pylori and 22 patient were negative H.pylori. our results indicated statistically significant decrease in the prevalence of $\mathrm{H}$. pylori infection among the bleeder group.

Keywords: Child-Pugh, H. pylori, esophageal varices.

\section{INTRODUCTION}

Helicobacter pylori is a Gram-negative 
bacillus, resistant to the activity of

gastric juice. The bacteria may take the

vegetative or sporulation form.

H.pylori lives mainly on the surface of epithelial cells of mucous membranes of the prepyloric part of the stomach. The cilia present on the bacteria allow it to move into intercellular spaces and adhere to the surface of the cells. Infection with these bacteria is one of the most common infection in the world (1).

Inflammatory changes in the stomach caused by Helicobacter pylori indirectly and directly affect liver function.

Moreover, the bacteria may worsen the course of the liver cirrhosis. H. pylori infection is significantly more frequent among patients with post inflammatory liver cirrhosis related to $\mathrm{HCV}$ or $\mathrm{HBV}$ infection than in patients with alcoholic liver cirrhosis or primary biliary cirrhosis. ${ }^{(2)}$

The incidence of esophageal varices correlates with the incidence of H. pylori infection. Also, there is significant association between Helicobacter pylori infection and portal hypertensive gastropathy (PHG) in cirrhotic patients, also related to PHG severity, thereby necessitating $H$. pylori eradication. ${ }^{(3)}$

\section{PATIENTS AND METHODS}

The current study is a prospective case control study conducted on 150 patients admitted at Dar Elsalam Hospitals and EL Fayoum general Hospital with chronic liver diseases and portal hypertension after given their informed consent to the study

\section{All patients are divided into three groups: GroupI: Contains 50 patients complaining of hematemesis as a result of bleeding Ovs. (bleeders group).} GroupII: Contains 50 patients attending 
to endoscopy unit for prophylactic

treatment of Ovs. (non bleeders

group). GroupIII: Contains 50 patients

with chronic liver disease without Ovs as

\section{a (control group).}

\begin{tabular}{|c|c|c|c|c|c|}
\hline & & $\begin{array}{l}\text { Blee } \\
\text { (No. }\end{array}$ & & Non & \\
\hline & & No & $\%$ & No & $\%$ \\
\hline & $\|$ & 8 & $16.0 \%$ & 18 & $36.0 \%$ \\
\hline OV grade & |||| & 20 & $40.0 \%$ & 18 & $36.0 \%$ \\
\hline & IV & 22 & $44.0 \%$ & 14 & $28.0 \%$ \\
\hline
\end{tabular}

Table (2): OV grade in studied groups

\section{Results}

\begin{tabular}{|c|c|c|c|c|c|c|c|c|c|}
\hline & & \multicolumn{2}{|c|}{$\begin{array}{l}\text { Non bleeding } \\
\text { (No.50) }\end{array}$} & \multicolumn{2}{|c|}{$\begin{array}{l}\text { Bleeding } \\
\text { (No.50) }\end{array}$} & \multicolumn{2}{|c|}{$\begin{array}{l}\text { Control } \\
\text { (No.50) }\end{array}$} & \multicolumn{2}{|c|}{$\begin{array}{l}\text { Chi square test/ } \\
\text { one way ANOVA }\end{array}$} \\
\hline & & No & $\%$ & No & $\%$ & No & $\%$ & $x^{2}$ & $P$ value \\
\hline \multirow{2}{*}{ Age } & Mean \pm SD & \multicolumn{2}{|c|}{$45.2 \pm 2.15$} & \multicolumn{2}{|c|}{$48.65 \pm 3.2$} & \multicolumn{2}{|c|}{$53.25 \pm 1.2$} & \multirow{2}{*}{0.165} & \multirow{2}{*}{0.354} \\
\hline & Range & \multicolumn{2}{|c|}{$30-70$} & \multicolumn{2}{|c|}{$35-70$} & \multicolumn{2}{|c|}{$35-70$} & & \\
\hline \multirow{3}{*}{ Sex } & Male & 27 & $54.0 \%$ & 26 & $52.0 \%$ & 28 & $56.0 \%$ & \multirow{3}{*}{0.161} & \multirow{3}{*}{0.922} \\
\hline & & & & & & & & & \\
\hline & Female & 23 & $46.0 \%$ & 24 & $48.0 \%$ & 22 & $44.0 \%$ & & \\
\hline
\end{tabular}

Table (1): Discription of demographic data (age and gender) in between the studied grc

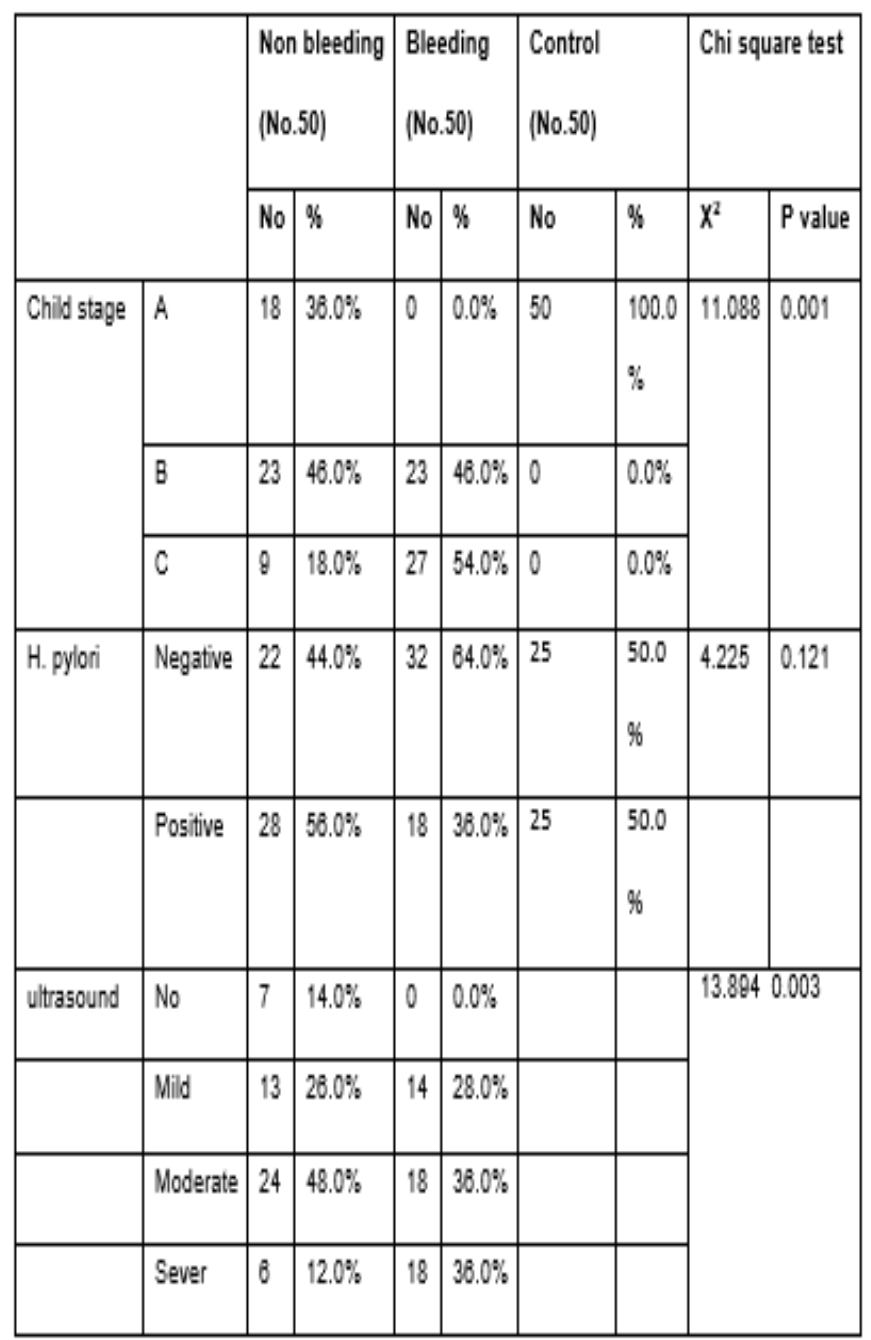

Table (3): child Pugh score, Hoxdori distribution and degree of acitis in the studied groups. 


\begin{tabular}{|c|c|c|c|c|c|c|c|c|}
\hline & \multicolumn{2}{|c|}{ Non bleeding } & \multicolumn{2}{|c|}{ Bleeding } & \multicolumn{2}{|c|}{$\begin{array}{l}\text { Control } \\
\text { (No.50) }\end{array}$} & \multicolumn{2}{|c|}{ one way ANOVA } \\
\hline & Mean & $S D$ & Mean & $S D$ & Mean & $S D$ & $t$ & Pvalue \\
\hline Bilirubin & 2.06 & 0.84 & 2.94 & 1.14 & 1.11 & 0.11 & $00,1 \leqslant\}$ & 0.001 \\
\hline Albumin & 3.67 & 4.08 & 2.39 & 0.63 & 4.64 & 0.56 & $11,\{\pi \mid$ & 0.001 \\
\hline
\end{tabular}

Table (4): Serum bilinubin and serum albumin in the studied group:

There was no statistically

significant difference between demographic data among studied groups(Table 1). From bleeding group 8 patients (16\%) were OV grade II and 20 patients (40\%) were OV grade III and 22 patients were OV grade IV (44\%) (Table 2). There was statistically significant increase stage A in control group and non-bleeding group and increase stage $\mathbf{C}$ in bleeding group and statistically significant increase $\mathrm{H}$. pylori in nonbleeding group. There was statistically significant difference between studied groups as regard to ascites in ultrasound. There was increase severe ascites in bleeding group but increase moderate ascites in non-bleeders group (Table 3). There was statistically significant difference between the studied groups as regard serum bilirubin and serum albumin (Table 4).

\section{DISCUSSION}

Cirrhosis of liver is a major problem in the world and is characterized by extensive fibrosis. Portal hypertension is a complication of cirrhosis and can lead to the development of gastrointestinal varices. (5)

Helicobacter pylori (H. pylori) are a worldwide gastrointestinal infection. there is a significant association between H. pylori infection and severity of gastropathy due to portal hypertension, chronic stomach upset and frequent 
upper gastrointestinal bleeding. ${ }^{(6)}$

The aim of our study was to

investigate $\mathrm{H}$. pylori infection among patients with liver cirrhosis and its correlation with the degree of liver injury according to Child-Pugh classification and the stage of esophageal varices and its bleeding.

This prospective case control study included 150 patients with chronic liver diseases and portal hypertension. They were recruited and assessed for eligibility from at Kasr AL-ainy Hospitals and EL Fayoum general Hospital and they were divided into three groups; A) bleeding group that included 50 patients complaining of haematemesis as a result of bleeding oesophageal varices (Ovs) or gastric, B) non-bleeders group that included 50 patients attending to endoscopy unit for prophylactic treatment of OVs C) a control group that included 50 patients with chronic liver disease without Ovs.

Regarding the demographic characteristics of the studied groups, our results indicated that the mean age of the non-bleeding, bleeding and control groups were $45.2 \pm 2.15 ; 48.65 \pm 3.2$ and $53.25 \pm 1.2$ respectively, with no statistically significant difference among the studied groups (P value=0.354)

There were no significant difference between the studied groups regarding genders $(\mathrm{P}$ value $=0.922)$. This study was a case control study with age and gender matched study groups to improve study efficiency by improving precision and avoiding the confounding effects of both age and gender in the statistical analysis. ${ }^{(7)}$

Regarding the severity of liver cirrhosis assessed by child-pugh class, our results indicated a statistically significant increase of category $A$ in control group (100\%) and increase of category C 
among the bleeding group while there

were increase in category $B$ among the non-bleeding group $(P=0001)$. A study

by Kumar et al. ${ }^{(8)}$ indicated that the prevalence of large esophageal varices in patients with advanced child-Pugh class was higher than that in patients with child-Pugh class A. Moreover, Cherian et al. ${ }^{(9)}$ also found that childPugh class B/C emerged as significant predictors for the presence of esophageal varices.

Among the bleeding group, regarding the child stage, our result indicated that $46 \%$ of patients were stage B and $54 \%$ were stage $\mathrm{C}$, moreover regarding the OVs grade, our result indicated that $17 \%$ of patients were OV grade II, $\_$• \% were OV grade III and $46 \%$ were grade VI. Such finding was in agreement with a previous study by Gunda et al. ${ }^{(10)}$ indicated that liver cirrhosis of ChildPugh $B / C$ was reported as an independent predictor of esophageal varices.

Among the bleeding group, regarding the prevalence of ascites, our results indicated that $72 \%$ of the cases have moderate to severe ascites and $28 \%$ has mild ascites. We observed a significant increase moderate and severe ascites among the bleeding group in comparison with the non-bleeding group regarding the grade of ascites $(\mathrm{P}$ value $=0.003$ ).

Such finding was in agreement with Gunda et al. ${ }^{(10)}$ that indicated high prevalence of ascites (94.3\%) among patients with esophageal varices and liver cirrhosis. A previous study by Hassanin et al. ${ }^{(11)}$ indicated that $53 \%$ of patients with cirrhotic liver have moderate to severe grade ascites.

Additionally, Kumar et al. ${ }^{(8)}$ study indicated that the prevalence of ascites among cirrhotic patients with grade III and IV esophageal varices was $78.26 \%$ 
while the prevalence of ascites among

cirrhotic patients with grade I and II esophageal varices was $62.96 \%$.

Our result indicated that no statistically significant differences in the prevalence of $\mathrm{H}$. pylori infection among the studied groups $(P$ value $=0.121)$. The frequency of $\mathrm{H}$. pylori infection in the nonbleeding, bleeding and control groups was $56 \%, 36 \%$ and $50 \%$ respectively. Such findings were in agreement with Eid et al. ${ }^{(12)}$ study that indicated no significant correlation between $\mathrm{H}$. pylori infection and the severity of liver cirrhosis. Pogorzelska et al. (2)indicated that the overall prevalence of $\mathrm{H}$. pylori infection in cirrhotic patients ranged from $35.1 \%$ to $70.6 \%$. This discrepancy is perhaps related to the different investigational tools used for the diagnosis of $\mathrm{H}$. pylori infection.

\section{A recent retrospective study by Guo et} al. ${ }^{(13)}$ indicated that patients who failed the initial $\mathrm{H}$ pylori eradication have an increased risk of upper gastrointestinal bleeding compared to patients who responded to the initial therapy and early retreatment within 3 months should be considered. On the other hand, our result was in disagreement with

Elsebaey et al. ${ }^{(14)}$ that indicated significant increase of the prevalence of H. pylori among the bleeding group in comparison with non-bleeding group.

Among the bleeding group, regarding the biochemical markers of varices, our results indicated that the mean of serum bilirubin was 2.94 with range from 1 to 4 and mean of serum albumin was 2.39 $\mathrm{mg} / \mathrm{dL}$ with range from 1.4 to $3.5 \mathrm{mg} / \mathrm{dL}$. Such findings were in agreement with Mohamed et al. ${ }^{(15)}$ that indicated that most of patients with cirrhosis presented with upper gastrointestinal bleeding have albumin levels less than $3.5 \mathrm{mg} / \mathrm{dL}$ and bilirubin level higher than $2 \mathrm{mg} / \mathrm{dL}$. A previous study by Budiyasa et al. 
(16)indicated that in esophageal varices

patients, the serum albumin level ranged

between $1.10-3.60 \mathrm{mg} / \mathrm{dL}$, the average

value was $2.21 \pm 0.451 \mathrm{mg} / \mathrm{dL}$ and that

serum albumin level can predict the

presence and the degree of EV in

patients with liver cirrhosis.

Our results indicated a statistically

significant difference regarding the

albumin and bilirubin levels among the studied groups $(\mathrm{P}$ value $=0.001)$. The

mean albumin level among the non-

bleeding, bleeding and control groups

was $3.67 \pm 4.08 ; 2.39 \pm 0.63$ and $4.64 \pm$

0.56 respectively. The mean bilirubin

level was $2.06 \pm 0.84 ; 2.94 \pm 1.14$ and

$1.11 \pm 0.11$ respectively. A previous

study indicated that the mean level of

bilirubin in patients with chronic liver

diseases and H. pylori infection was 2.7士

$0.5260 \mathrm{mg} / \mathrm{dl}$ that is consistent with our

results. ${ }^{17)}$ On the other hand, our result

was in disagreement with Gunda et al.

(10)that indicated no significant difference in serum albumin levels between those

with and without esophageal varices.

\section{Conclusion}

H. pylori infection is not a risk factor for bleeding from esophageal varices.

Child-Pugh class B/C emerged as significant predictor for the presence of esophageal varices.

\section{References}

.1 Mitchell, H. and Katelaris, $\mathbf{P}$. Epidemiology, clinical impacts and current clinical management of Helicobacter pylori infection. The Medical Journal of Australia,2016. 204(10): p. 376380.

.2 Pogorzelska, J., Lapińska, M., Kalinowska, A., Łapiński, T.W ,. and Flisiak, R. Helicobacter pylori infection among patients with liver cirrhosis. Eur J Gastroenterol Hepatol,2017. 29(10): p. 1161-1165.

.3 Kountouras, J., Deretzi, G., Zavos, C., and Katsinelos, $\mathbf{P}$. Helicobacter pylori infection and liver cirrhosis :possible association with hepatic encephalopathy and/or posthepatic encephalopathy cognitive impairment in patients with portal hypertension. Annals of gastroenterology,2014. p. 285285.

$.4 \quad$ Zych, W. and Habior, $\mathbf{A}$. Hemorrhage from esophageal varices. Post Nauk Med,2014. 1: p. 9-16. 
Simonetto, D.A., Liu, M., and

Kamath, P.S. Portal Hypertension and Related Complications:

Diagnosis and Management. Mayo Clinic Proceedings,2019. 94(4): p. 714-726.

Hamed, E.A. , Mohammad, S.A., Rawash Eldieb, L.M., and

Shalaby, M.H. Upper

gastrointestinal series in children:

what surgeons need to know.

Annals of Pediatric Surgery,2020. 16(1): p. 52.

.7 de Graaf, M.A., Jager, K.J., Zoccali, C., and Dekker, F.W. Matching, an Appealing Method to Avoid Confounding? Nephron Clinical Practice,201 1. 118(4): p. c315-c318.

Kumar, P., Singh, K. , Joshi, A., Thakur, P., Mahto, S.K., Kumar, B., Pasricha, N., Patra, B.R., and Lamba, B.M.S. Evaluation of non-invasive marker of esophageal varices in cirrhosis of liver. J Family Med Prim Care,2020. 9(2): p. 992-996.

Cherian, J., Deepak, N., Ponnusamy, R.,

Somasundaram, $\mathbf{A}$., and Jayanthi, V. Non-invasive predictors of esophageal varices. Saudi Journal of Gastroenterology,2011. 17(1): p. 64-68.

.10 Gunda, D.W., Kilonzo, S.B., Mamballah, Z. , Manyiri, P.M., Majinge, D.C., Jaka, H., Kidenya, B.R., and Mazigo, H.D. The magnitude and correlates of esophageal Varices among newly diagnosed cirrhotic patients undergoing screening fibre optic endoscope before incident bleeding in NorthWestern Tanzania; a crosssectional study. BMC
Gastroenterol,2019. 19(1): p. 203203.

.11 Hassanin, T.M., Foaud, Y., Mohamed, H., Saad, Z., Elsayed, A., Refaei, S., and Soliman, W. Prevalence and risk factors of endoscopically confirmed gastroesophageal reflux disease (GERD) in patients with liver cirrhosis. Egyptian Liver Journal,2021. 11(1): p. 27.

Eid, K., Shawky, M. , Hassan, A. , Mohammed, A., and Mohammed, M. Prevalence of $<$ i $>$ Helicobacter pylori $</ i>$ infection in patients with portal hypertensive gastropathy owing to liver cirrhosis in Upper Egypt. Al-Azhar Assiut Medical Journal,2016. 14(3): p. 109-114. Guo, C.-G., Cheung, K.S., Zhang, F., Chan, E.W., Chen, L., Wong, I.C., and Leung, W.K. Delay in retreatment of Helicobacter pylori infection increases risk of upper gastrointestinal bleeding. Clinical Gastroenterology and Hepatology,2021. 19(2): p. 314322. e2.

.14 Elsebaey, M.A., Tawfik, M.A., Elshweikh, S.A., Negm, M.S., Elnaggar, M.H., Alghazaly, G.M., and Abd-Elsalam, S. Impact of Helicobacter pylori Infection on Gastric Variceal Bleeding among Patients with Liver Cirrhosis. Gastroenterology Research and Practice,2019. 2019: p. 6529420.

.15 Mohamed, M.S., Hamed, M.G., Hanafy, A.S., and Bassiony, M.A. Clinical Outcomes of Upper Gastrointestinal Bleeding in Egyptian Patients with Decompensated Liver Cirrhosis, Does the Bleeding Source Matter? 
The Egyptian Journal of Hospital

Medicine,2020. 81(5): p. 2001-

2005.

.16 Budiyasa, D.G.A., Ariawan, Y., Mariadi, I.K., Wibawa, I.D.N., Purwadi, N , and Suryadarma, I.G.A. Correlation between serum albumin level and degree of esophageal varices in patients with liver cirrhosis. Indonesian Journal of Gastroenterology, Hepatology, and Digestive Endoscopy,201 1. 12(1): p. 23-27.

.17 Biswas, D.K. and Chakraborty, D.A. Helicobacter Pylori have positive association in developing peptic ulcers in patients with chronic liver diseases-an experience from Eastern India. 2018. 